\title{
Cycloartane Triterpenes from the Aerial Parts of Actaea racemosa
}

Ayano Imai, ${ }^{\dagger+}$ David C. Lankin,,${ }^{\dagger \ddagger}$ Dejan Nikolić,,+ Soyoun Ahn,,${ }^{\dagger+}$ Richard B. van Breemen, ${ }^{\dagger+}$ Norman R. Farnsworth, ${ }^{\dagger \$}$ James B. McAlpine, ${ }^{\ddagger}$ Shao-Nong Chen,${ }^{\dagger \neq}$ and Guido F. Pauli ${ }^{\dagger *}$

HUIC/NIH Center for Botanical Dietary Supplements Research, "Department of Medicinal Chemistry and Pharmacognosy, College of Pharmacy, University of Illinois at Chicago, Chicago, IL 60612, United States

** Deceased September 10, 2011

\section{ص SUPPORTING INFORMATION}

No. Content Page

S1 ROESY Spectrum of $1(700 \mathrm{MHz})$ in Pyridine- $d_{5} \quad \mathrm{~S}-2$

S2 gCOSY Spectrum of $1(900 \mathrm{MHz})$ in Pyridine- $d_{5} \quad$ S-3

S3 Multiplicity Edited gHSQC Spectrum of $1(700 \mathrm{MHz})$ in Pyridine- $d_{5} \quad$ S-4

S4 gHMBC Spectrum of $1(700 \mathrm{MHz})$ in Pyridine- $d_{5} \quad$ S-5

S5 $\quad{ }^{1} \mathrm{H}$ NMR Spectrum of $2(900 \mathrm{MHz})$ in Pyridine- $d_{5} \quad$ S-6

S6 gCOSY Spectrum of $2(600 \mathrm{MHz})$ in Pyridine- $d_{5} \quad$ S-7

S7 gHMBC Spectrum of $2(600 \mathrm{MHz})$ in Pyridine- $d_{5} \quad$ S-8

S8 gHSQC Spectrum of $2(600 \mathrm{MHz})$ in Pyridine- $d_{5} \quad$ S-9

S9 $\quad{ }^{1} \mathrm{H}$ NMR Spectrum of $3(900 \mathrm{MHz})$ in Pyridine- $d_{5} \quad$ S-10

S10 $\quad{ }^{1} \mathrm{H}$ NMR Spectrum of $4(900 \mathrm{MHz})$ in Pyridine- $d_{5} \quad$ S-11

S11 ${ }^{1} \mathrm{H}$ NMR Spectrum of $5(900 \mathrm{MHz})$ in Pyridine- $d_{5} \quad$ S-12

S12 ${ }^{1} \mathrm{H}$ NMR Spectrum of $6(900 \mathrm{MHz})$ in Pyridine- $d_{5} \quad$ S-13

S13 $\quad{ }^{1} \mathrm{H}$ NMR Spectrum of $7(900 \mathrm{MHz})$ in Pyridine- $d_{5} \quad$ S-14

S14 ${ }^{1} \mathrm{H}$ NMR Spectrum of $8(900 \mathrm{MHz})$ in Pyridine- $d_{5} \quad$ S-15

S15 ${ }^{1} \mathrm{H}$ NMR Spectrum of $9(900 \mathrm{MHz})$ in Pyridine- $d_{5} \quad$ S-16 


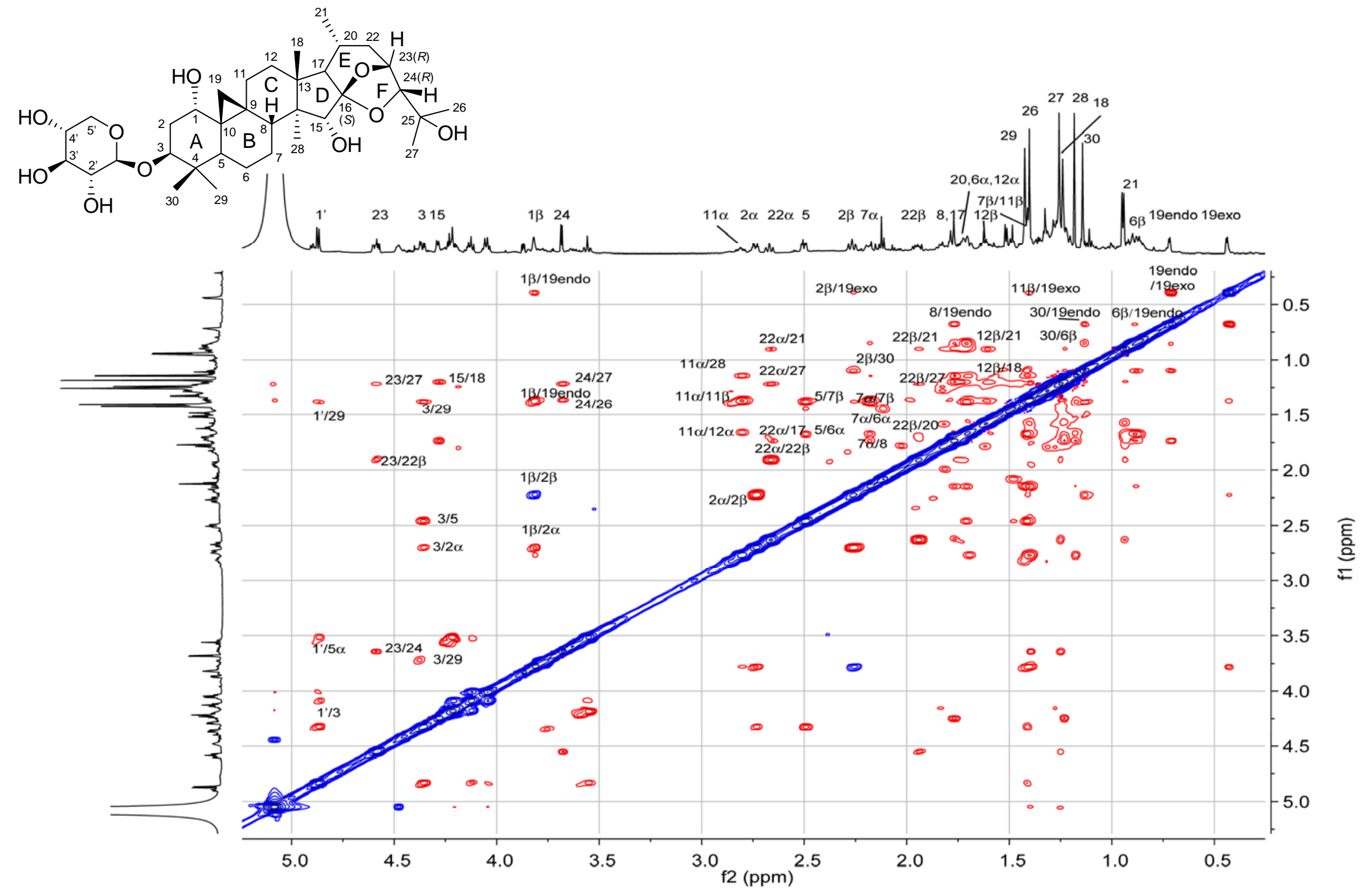

Figure S1. ROESY spectrum of $1(700 \mathrm{MHz})$ in pyridine- $d 5$. 


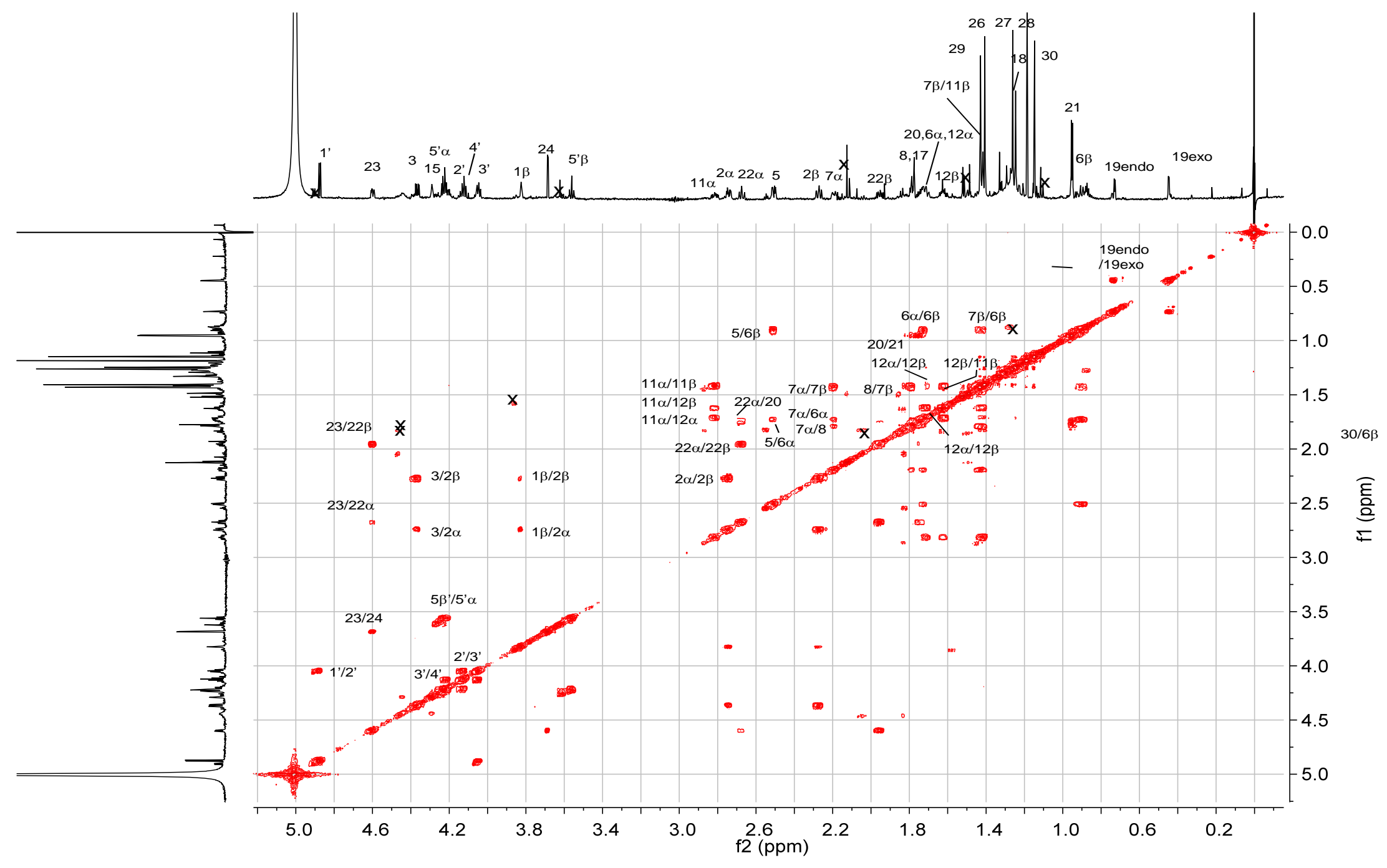

Figure S2. gCOSY spectrum of $1(900 \mathrm{MHz})$ in pyridine- $d 5$. 


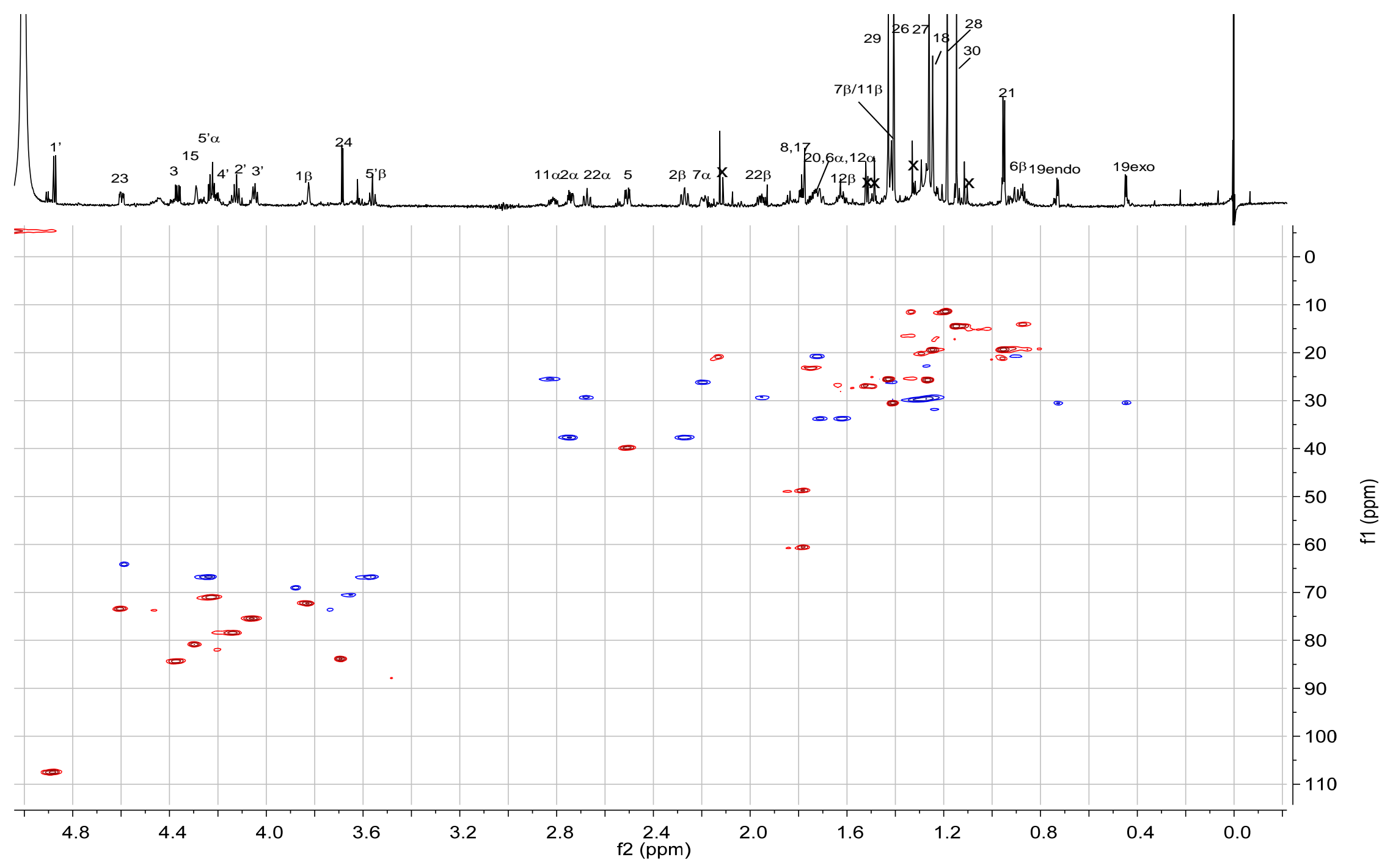

Figure S3. Multiplicity edited gHSQC spectrum of $1(700 \mathrm{MHz})$ in pyridine- $d 5$. 


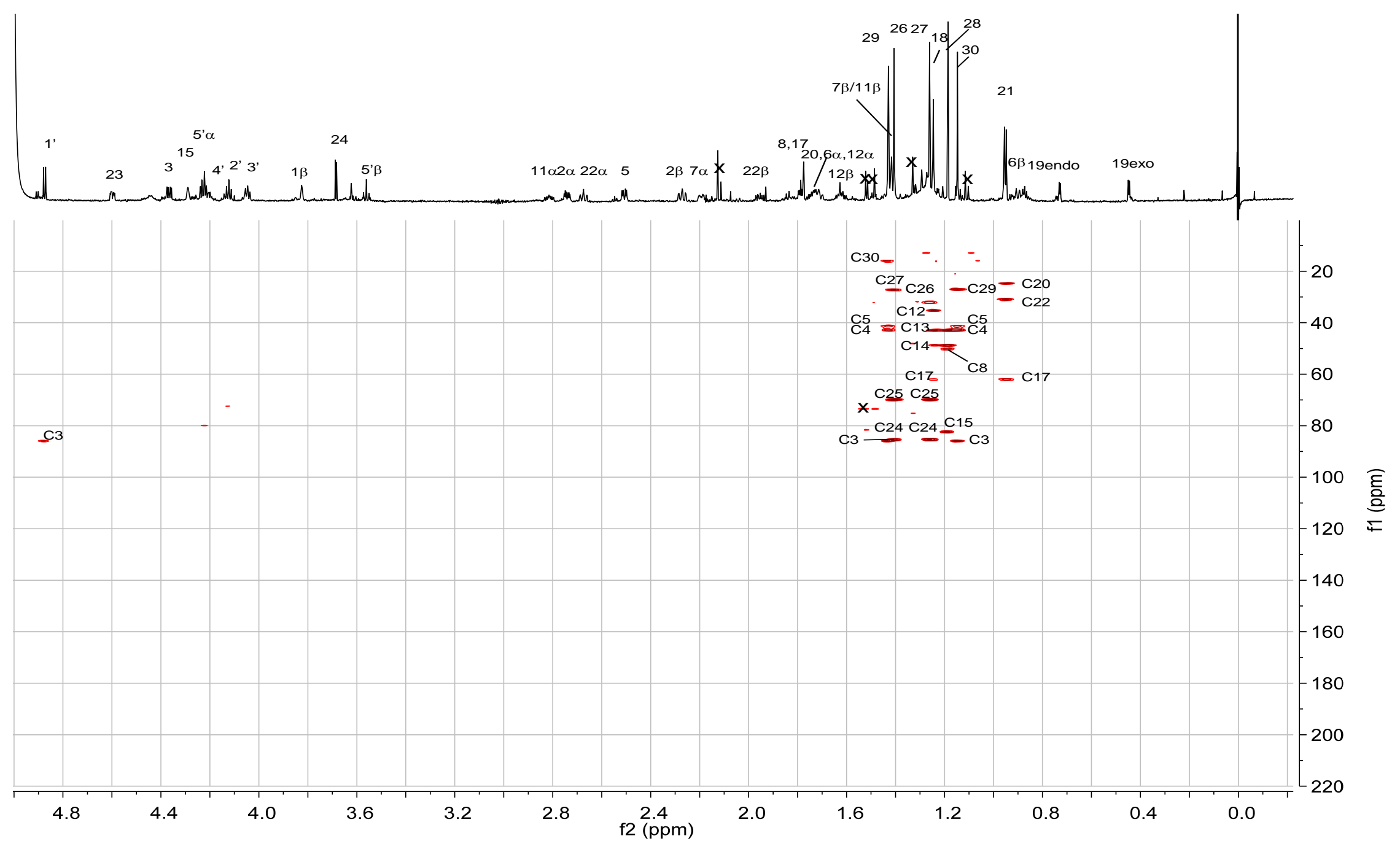

Figure S4. gHMBC spectrum of 1 (700 MHz) in pyridine- $d_{5}$. 

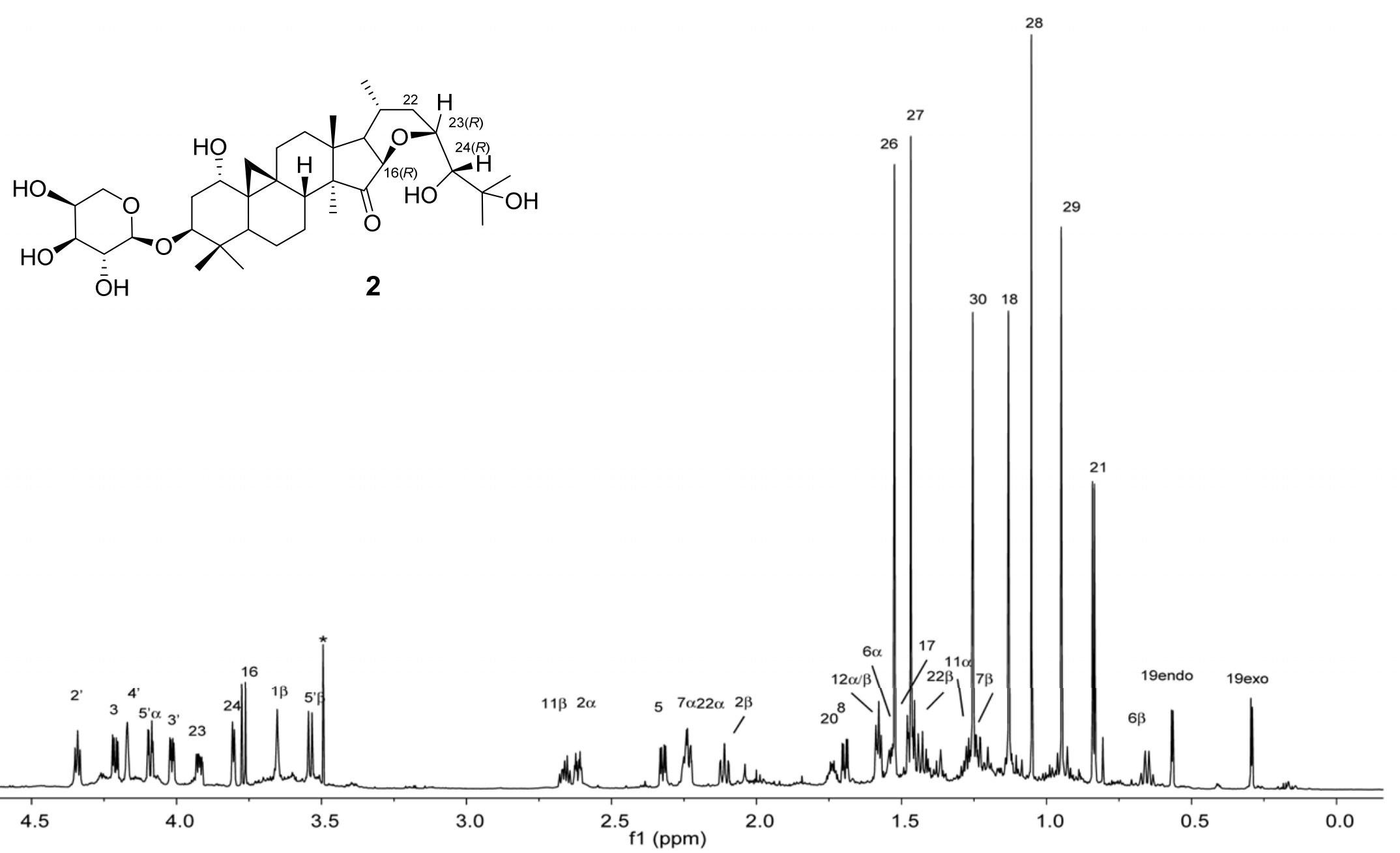

Figure S5. ${ }^{1} \mathrm{H}$ NMR spectrum of $2(900 \mathrm{MHz})$ in pyridine- $d 5$. The (*) indicates residual $\mathrm{MeOH}$. 


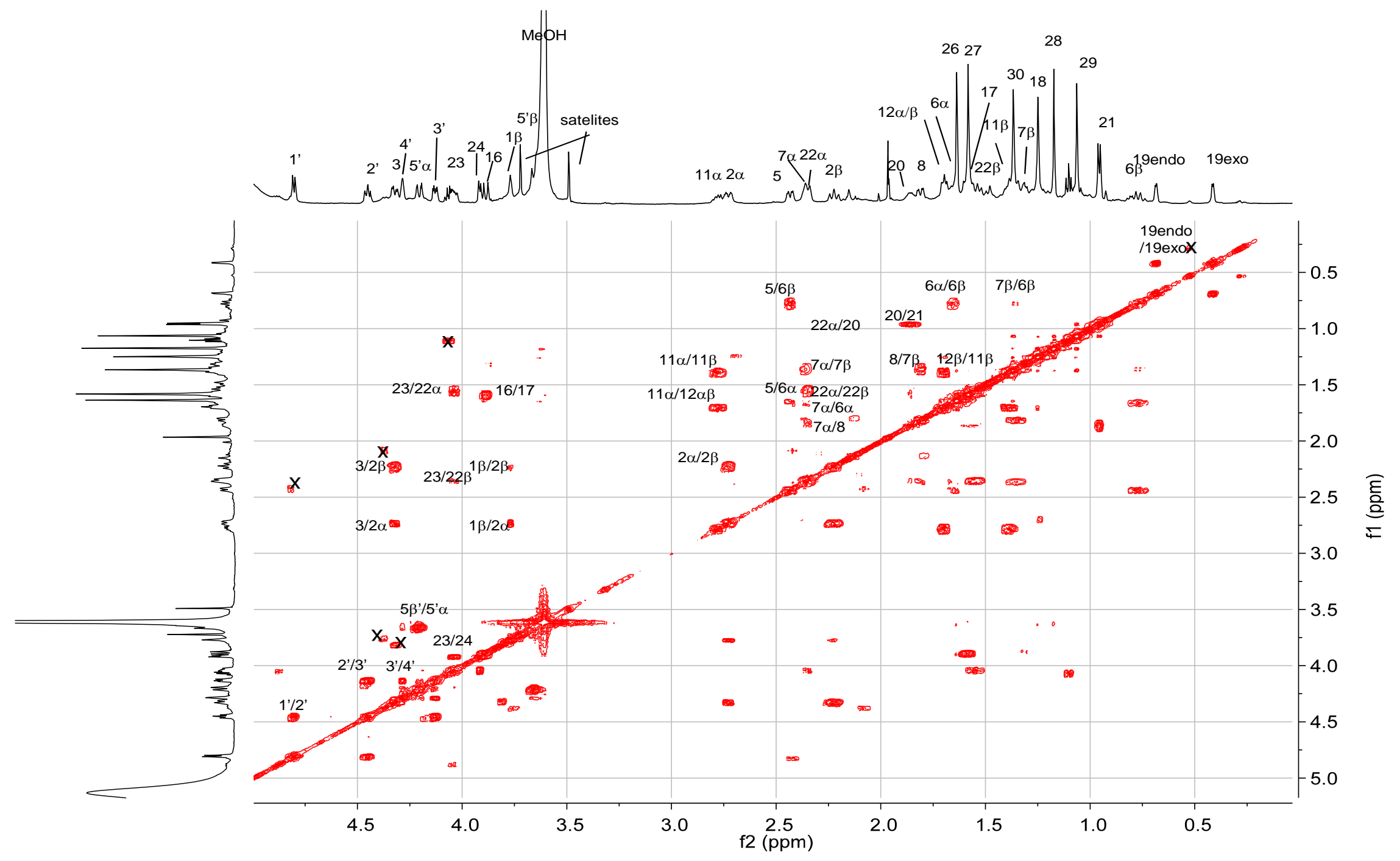

Figure S6. gCOSY spectrum of $2(600 \mathrm{MHz})$ in pyridine- $d 5$. 


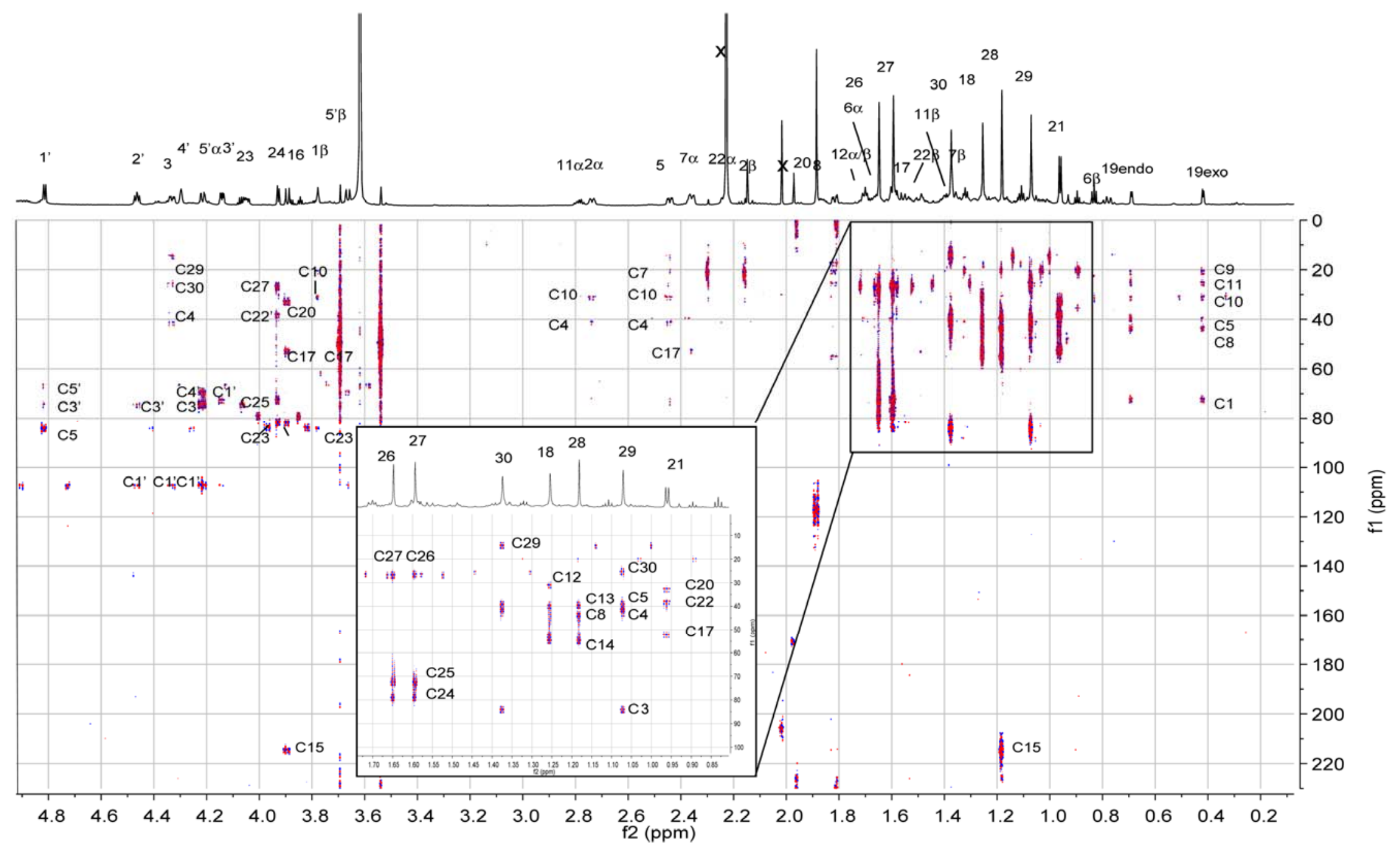

Figure S7. gHMBC spectrum of $2(600 \mathrm{MHz})$ in pyridine $d 5$. 


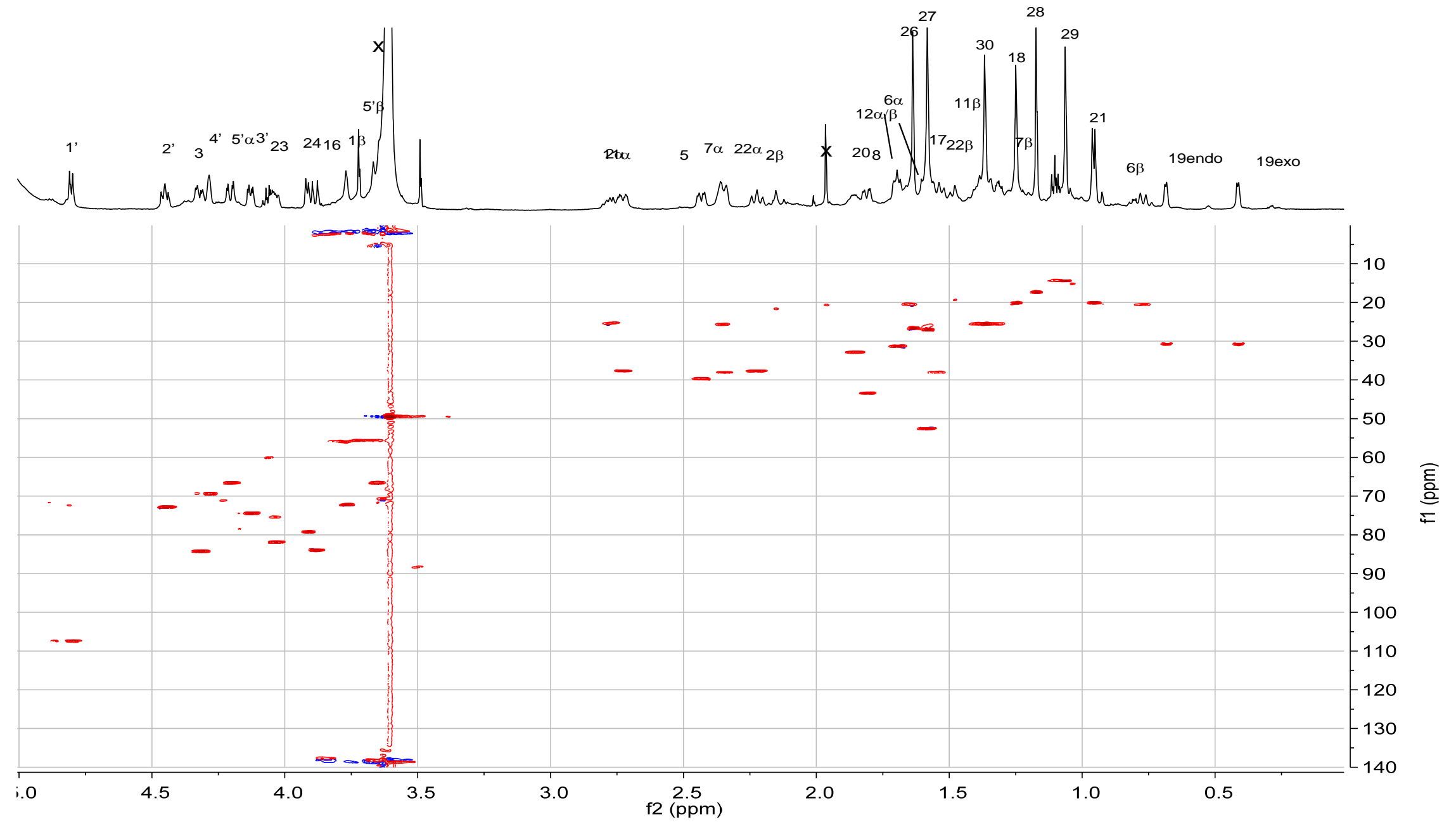

Figure S8. gHSQC spectrum of $2(600 \mathrm{MHz})$ in pyridine- $d_{5}$. 

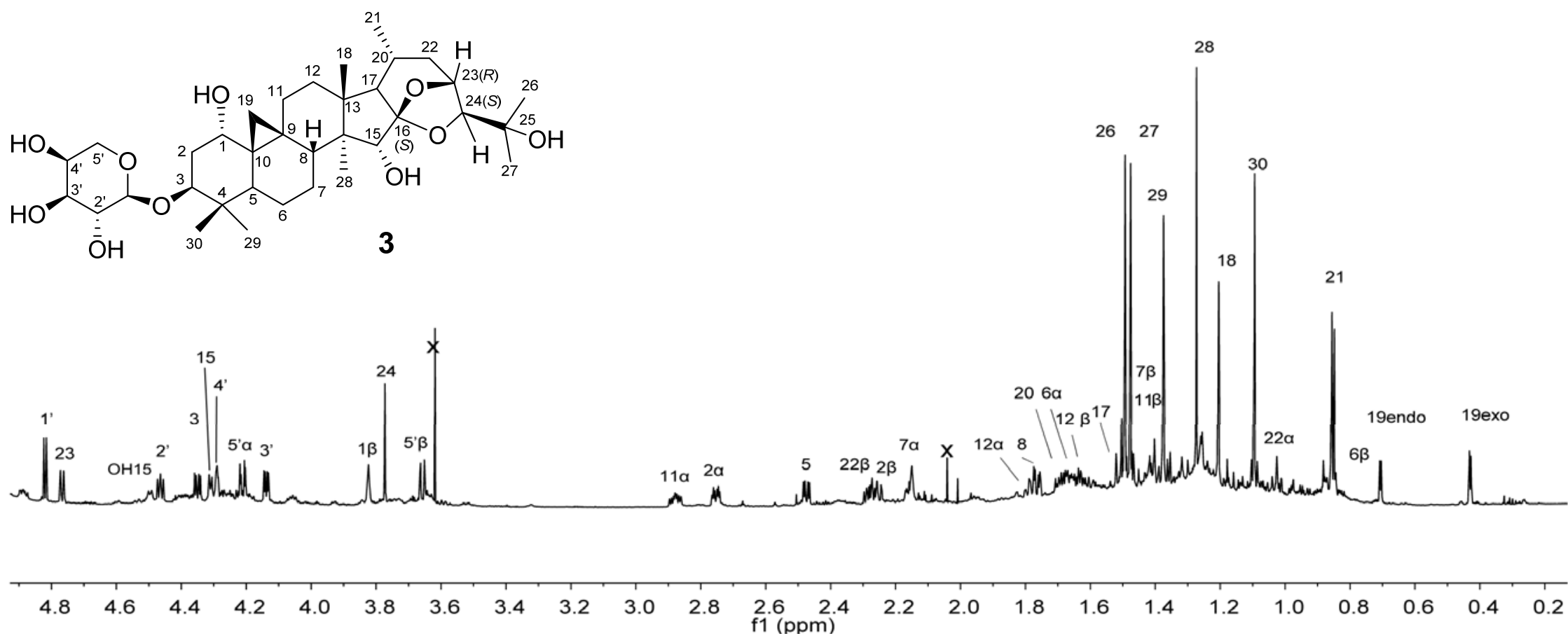

Figure S9. ${ }^{1} \mathrm{H}$ NMR spectrum of $\mathbf{3}(900 \mathrm{MHz})$ in pyridine- $d 5$. 


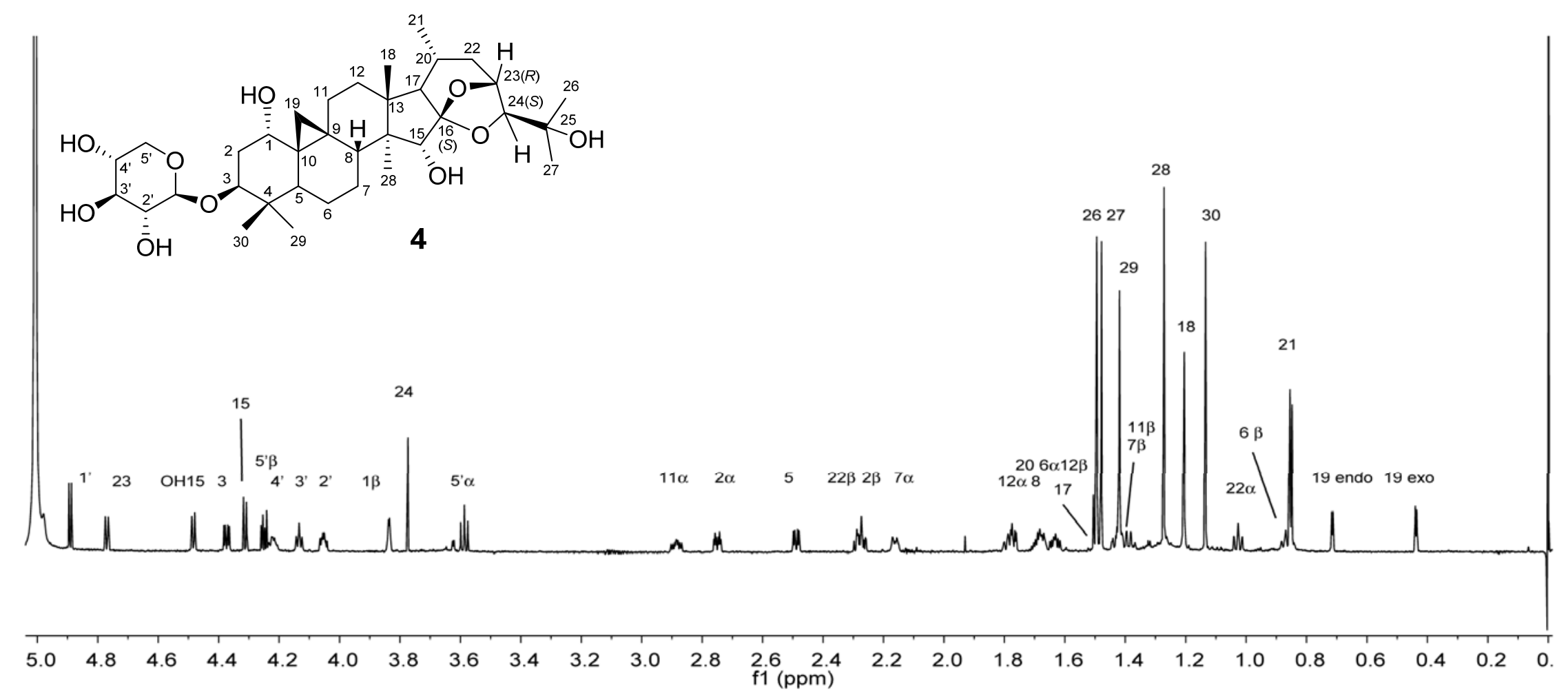

Figure S10. ${ }^{1} \mathrm{H}$ NM R spectrum of $4(900 \mathrm{MHz})$ in pyridine- $d 5$. 

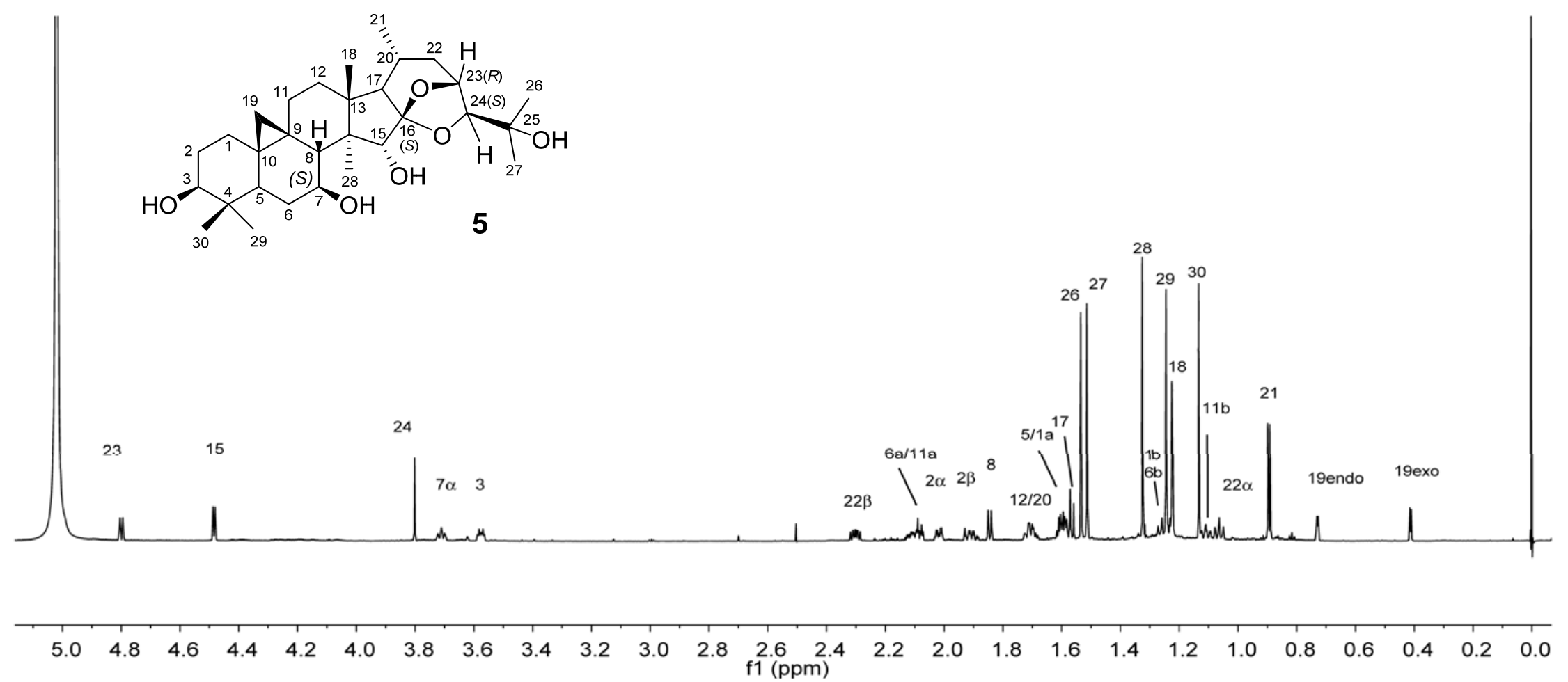

Figure S11. ${ }^{1} \mathrm{H}$ NMR spectrum of $5(900 \mathrm{MHz})$ in pyridine- $d 5$. 


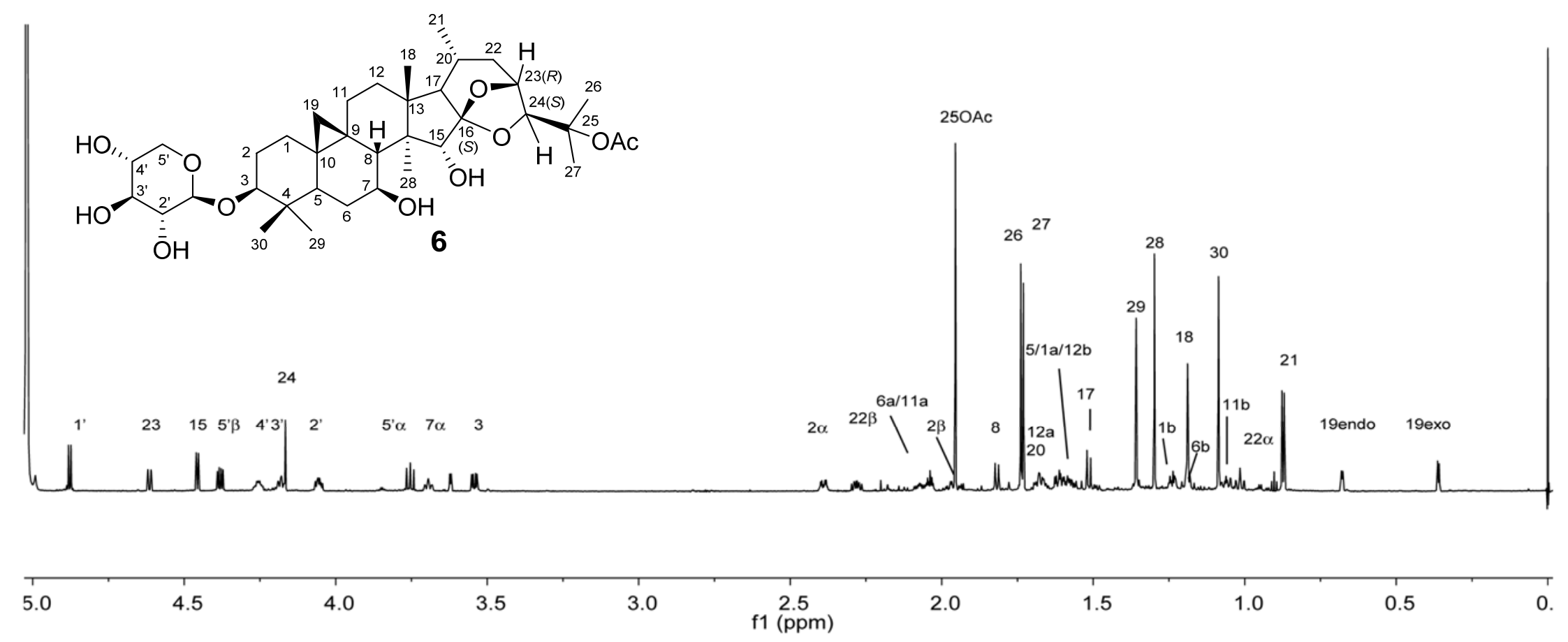

Figure S12. ${ }^{1} \mathrm{H}$ NMR spectrum of $6(900 \mathrm{MHz})$ in pyridine- $d 5$. 

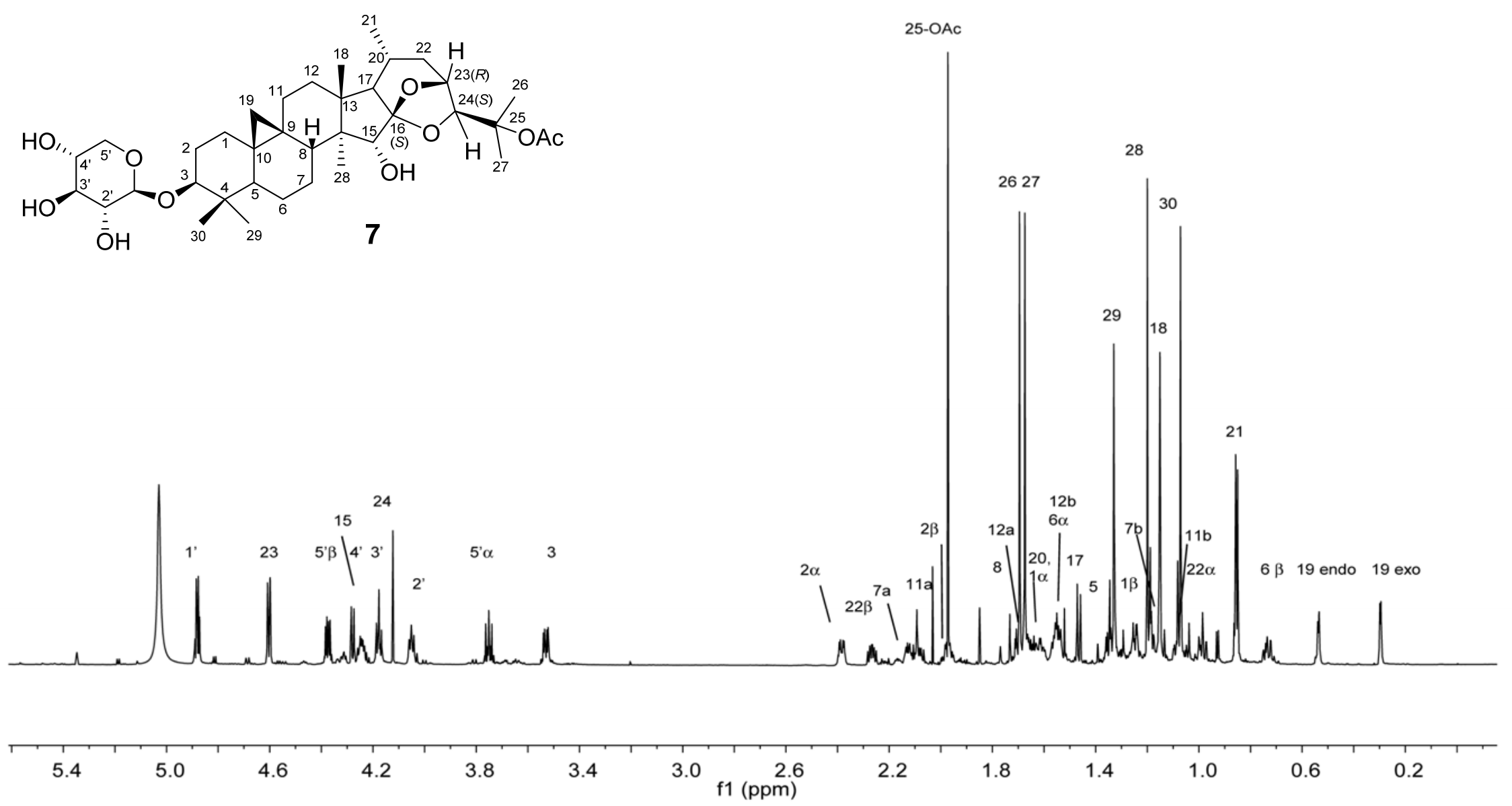

Figure S13. ${ }^{1} \mathrm{H}$ NMR spectrum of $7(900 \mathrm{MHz})$ in pyridine- $d s$. 


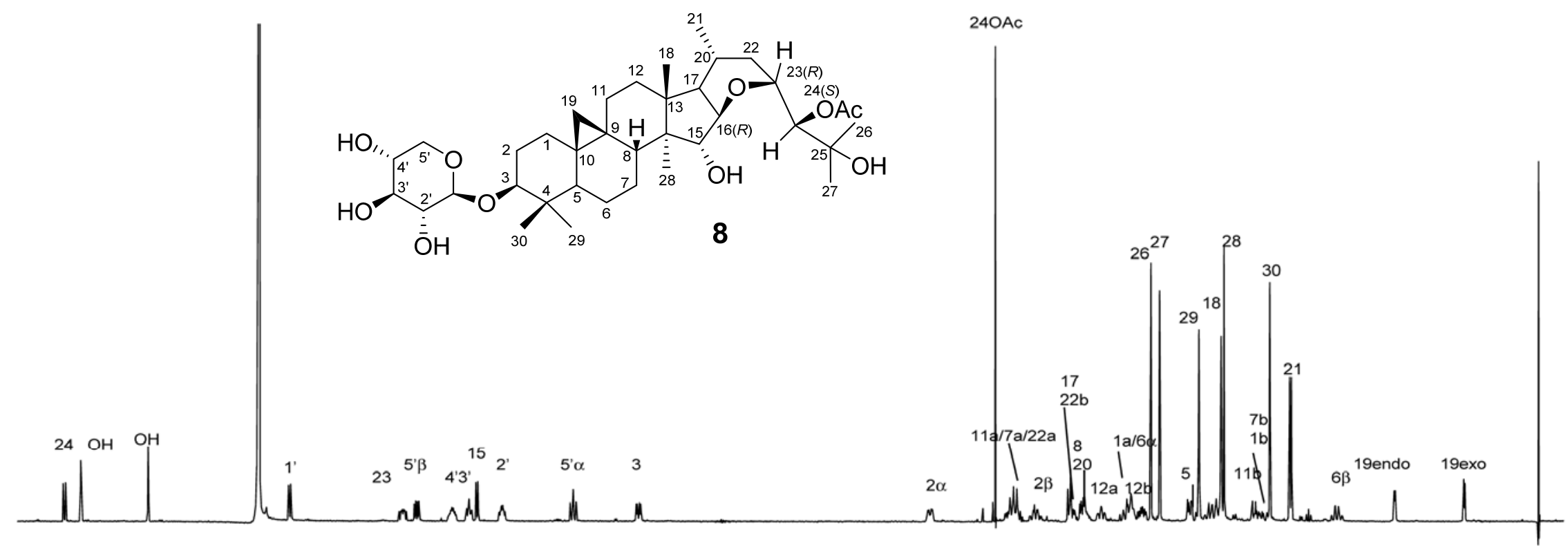

$22 \beta$

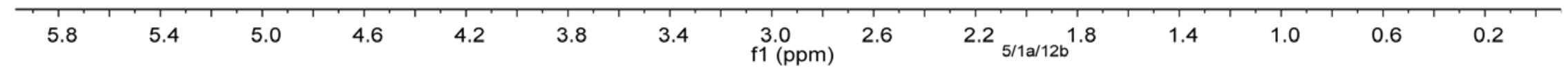

Figure S14. ${ }^{1} \mathrm{H}$ NMR spectrum of $8(900 \mathrm{MHz})$ in pyridine- $d 5$. 


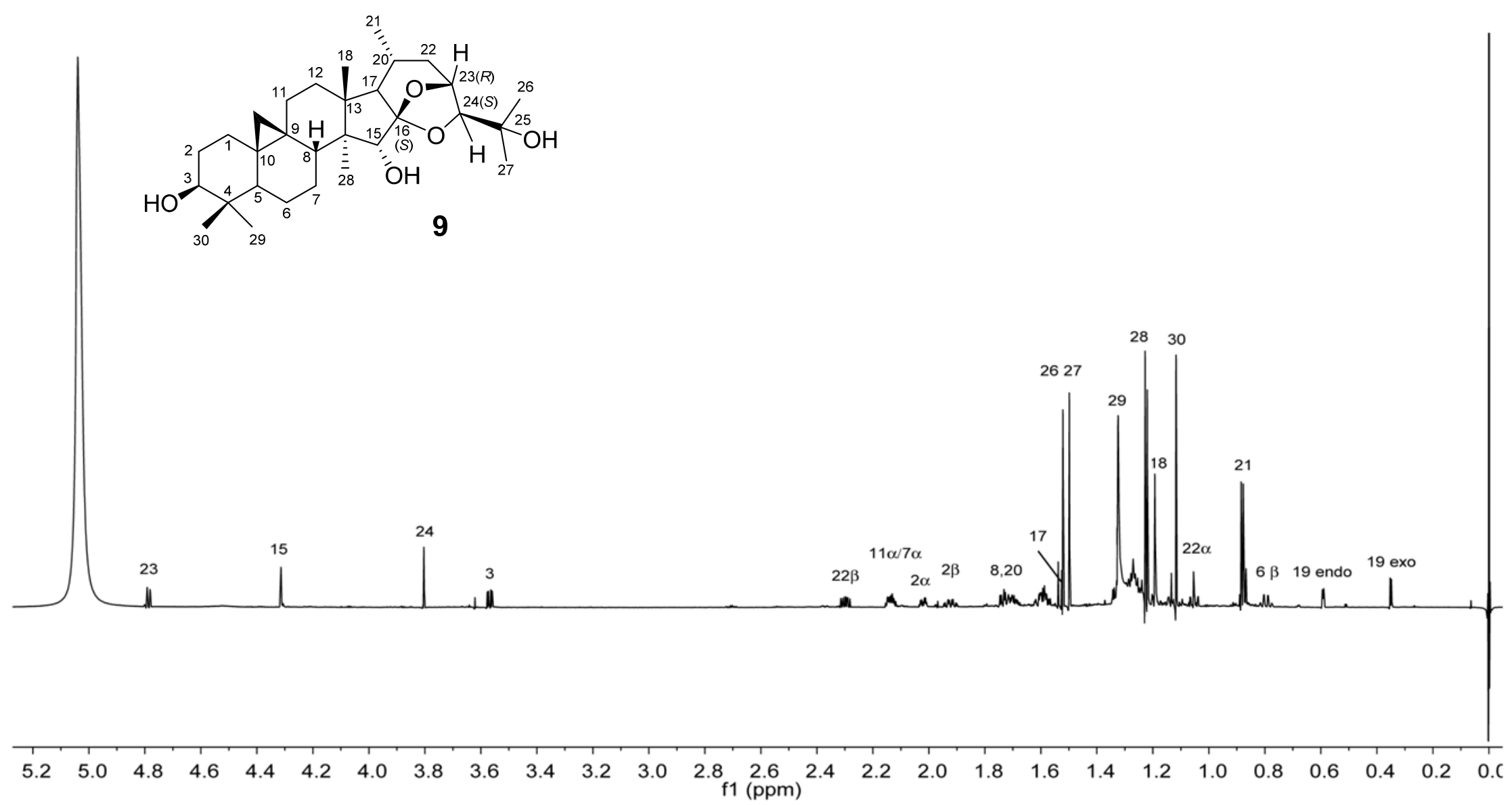

Figure S15. ${ }^{1} \mathrm{H}$ NMR spectrum of $9(900 \mathrm{MHz})$ in pyridine- $d 5$. 